\title{
What Does It Take to Establish New Paradigms?
}

\author{
Christoph Thomssen $^{a}$ Regina Grosse ${ }^{a}$ Thorsten Kühn ${ }^{b}$

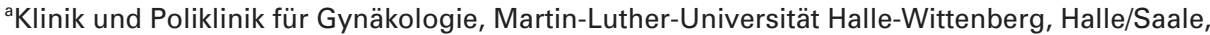 \\ ${ }^{b}$ Frauenklinik, Städtische Kliniken Esslingen a.N., Esslingen, Germany
}

Breast cancer is becoming a curable disease. Some of the reasons for this are the improvement of early detection, screening and improved imaging. Thus, in many countries there is a clear trend that breast tumors tend to be smaller when diagnosed. Focus of this issue of BREAST CARE are new developments in breast imaging, reported and discussed by highly experienced specialists [1-5].

Another reason why breast cancer is turning into a curable disease is the consequent and well standardized treatment of early breast cancer with regard to adjuvant therapy. According to the EBCTCG overview [6], even with traditional adjuvant therapies, i.e. without using taxanes, trastuzumab, and aromatase inhibitors, up to $60 \%$ of deaths can be avoided over a period of 15 years compared with untreated patient cohorts. However, this strategy also results in substantial overtreatment and tailoring treatment is a modern issue. Thus, this years' St. Gallen Consensus Conference on Early Breast Cancer focused on individualizing therapy with the motto: 'Strategies for subtypes. Dealing with the diversity of breast cancer'. In this issue of BREAST CARE, the editors report on their impressions of the 2011 St. Gallen Consensus Panel results, where the minimal strategies of breast cancer care for the next two years were agreed upon [7]. In a second contribution, German breast cancer experts refer to their perception of the St. Gallen results 2011 and discuss how they would implement the consensus statements into the practice of breast cancer care in Germany [8].

Progression in tailoring treatment has also been achieved with regard to local therapy - surgery and radiotherapy. Last year, the results of two pivotal randomized trials were published. Here, we would like to draw the reader's attention to an imbalance of the perceived validity of the results: In the TARGIT trial, intraoperative partial breast irradiation (IORT) was compared with standard radiotherapy in breast conserving treatment [9]. It was shown that IORT is not inferior to standard breast irradiation therapy, although IORT was performed only once during the operation. Supposing the same efficacy and safety, obviously, such a therapy would be much more comfortable for our patients when compared to 6 weeks of radiotherapy. The major weakness of this trial report is the rather short follow-up period. Therefore, especially in Germany, most radio-oncologists do not consider this therapy to be ready for routine implementation.

A second trial report deals with omitting axillary dissection in $\mathrm{pN} 1 \mathrm{sn}$ patients [10]. In a randomized trial on patients with 1 or 2 tumor infiltrated sentinel lymph nodes, the authors did not find the sentinel lymph node excision alone (SLND) to be inferior to standard axillary dissection (ALND) with respect to locoregional recurrences and overall survival. In the ongoing discussion, including the updated 2011 AGO guidelines (www.ago.online.de), these results were considered to be sufficient to no longer recommend axillary dissection in patients who fulfill all the inclusion criteria of the above-named trial (cN0, pT1 or pT2, breast conserving therapy, tangential irradiation, $\leq 2$ tumor infiltrated lymph nodes), although several weaknesses of this trial are obvious. Implementing this recommendation implies a major paradigm shift in the local therapy of breast cancer. The results of this trial were deemed sufficient to justify this step although the trial appears to lack power. Only $46 \%$ of planned recruitment was achieved, and axillary recurrence is per se a rare event. Furthermore, about $19 \%$ of all randomized patients were lost to follow-up. In addition, selection bias is obvious, since patients in the axillary dissection group had more factors pertaining to risk of recurrence than those in the sentinel group: only $37.5 \%$ micrometastases in the SNLD group and $44.8 \%$ in the ALND group ( $\mathrm{p}=0.05)$; in the ALND group, 199 patients had 1 tumor infiltrated sentinel node only, while in the SLND group 295 had 1 positive node only ( $\leq 2$ positive lymph nodes: ALND $77.8 \%$; SLND $89.4 \%$ ). Interestingly, in the multivariate analysis, the imbalanced factors that are discussed above were not considered, and the hazard ratio was only adjusted for rather well matched factors such as tumor size, receptor status, grading, and tumor type.

\section{KARGER}

Fax +497614520714

Information@Karger.de

www.karger.com (c) 2011 S. Karger GmbH, Freiburg

1661-3791/11/0062-0083\$38.00/0

Accessible online at:

www.karger.com/brc
Prof. Dr. med. Christoph Thomssen

Klinik und Poliklinik für Gynäkologie

Martin-Luther-Universität Halle-Wittenberg

Ernst-Grube-Strasse 40, 06097 Halle / Saale, Germany

Tel. +49 345 557-1847, Fax -1501

christoph.thomssen@medizin.uni-halle.de 
In summary, the results of both trials reflect a promising development. But both trial reports are characterized by substantial weaknesses. Considering the troublesome side effects of axillary dissection, it would be desirable to abandon this procedure even as therapeutic approach. Considering the amount of time that patients currently invest in radiotherapy, it would be helpful to have a 'one shot'-radiotherapy instead of 6 weeks of treatment. However, the data presented to date may not be mature enough - and perhaps it is too early to abandon the current standard treatment.

We should judge the results of both trials by the same strict criteria. In order to establish intraoperative partial breast irradiation, validating the results with a longer follow-up could be sufficient. To abandon axillary dissection, a second confirmatory trial with good stratification of known risk factors, such as size of tumor infiltration, number of infiltrated sentinel lymph nodes, and presence of vessel invasion, could be necessary [11]. In conclusion, even procedures with long-standing tradition should be challenged. However, a total change of treatment paradigms must be supported by evidence, not just by intuition.

\section{Disclosure Statement}

The authors declare no conflicts of interests.

\section{References}

1 Siegmann KC, Krämer B, Claussen C: Current status and new developments in breast MRI. Breast Care 2011;6: DOI: 10.1159/000328273.

2 Kettritz U: Minimally invasive biopsy methods - diagnostics or therapy? Personal opinion and review of the literature. Breast Care 2011;6: DOI $10.1159 / 000327889$.

3 Weismann CF, C Mair C, Egger H, Auer A: Breast sonography - 2D, 3D, 4D ultrasound, or elastography? Breast Care 2011;6: DOI: 10.1159/000327504.

4 Biesheuvel C, Weigel S, Heindel W: Mammogra phy screening: evidence history and current practice in germany and other european countries. Breast Care 2011;6: DOI: 10.1159/000327493.
5 Pinker K, Bogner W, Gruber S, Brader P, Trattnig S, Karanikas G, Helbich TH: Molecular imaging in breast cancer - potential future aspects. Breast Care 2011;6: DOI: 10.1159/000328275.

6 Early Breast Cancer Trialists' Collaborative Group (EBCTCG): Effects of chemotherapy and hormonal therapy for early breast cancer on recurrence and 15-year survival: an overview of the randomised trials. Lancet 2005;365:1687-717.

7 Gnant M, Harbeck N, Thomssen C: St. Gallen 2011: summary of the consensus discussion. Breast Care 2011;6: DOI: 10.1159/000328054.

8 Untch M, Gerber B, Möbus V, Schneeweiss A, Thomssen C, von Minckwitz G et al.: Zurich consensus: statement of German experts on St. Gallen conference 2011 on primary breast cancer (Zurich 2011). Breast Care 2011;6: DOI: 10.1159/000327999.
9 Vaidya JS, Baum M, Tobias JS, Wenz F, Massarut S, Keshtgar M, Hilaris B, Saunders C, Williams NR, Brew-Graves C, Corica T, Roncadin M, Kraus-Tiefenbacher U, Sütterlin M, Bulsara M, Joseph D: Long-term results of targeted intraoperative radiotherapy (Targit) boost during breast-conserving surgery. Int J Radiat Oncol Biol Phys 2010: 10.1016/j.ijrobp.2010.07.1996.

10 Giuliano AE, Hunt KK, Ballman KV, Beitsch PD, Whitworth PW, Blumencranz PW, Leitch AM, Saha S, McCall LM, Morrow M: Axillary dissection vs no axillary dissection in women with invasive breast cancer and sentinel node metastasis: a randomized clinical trial. JAMA 2011;305:569-575.

11 van la Parra RF, Peer PG, Ernst MF, Bosscha K: Meta-analysis of predictive factors for non-sentinel lymph node metastases in breast cancer patients with a positive SLN. Eur J Surg Oncol 2011;37:290 299. 